\title{
Atmospheric Moisture Condensation to Water Recovery by Home Air Conditioners
}

\author{
${ }^{1,3}$ Amir Hossein Mahvi, ${ }^{1,2}$ Vali Alipour and ${ }^{2}$ Leila Rezaei \\ ${ }^{1}$ Department of Environmental Health Engineering, \\ School of Public Health, Tehran University of Medical Sciences, Tehran, Iran \\ ${ }^{2}$ Hormozgan Environmental and Occupational Health Engineering Research Center, \\ Hormozgan University of Medical Sciences, Bandar Abbas, Iran \\ ${ }^{3}$ Center for Solid Waste Research, \\ Institute for Environmental Research, Tehran University of Medical Sciences, Tehran, Iran
}

Received 2013-07-07, Revised 2013-07-21; Accepted 2013-07-22

\begin{abstract}
Earth's atmosphere contains billion cubic meters of fresh water, which is considerable as a reliable water resource, especially in sultry areas. What is important in this context, how to extract the water, in an economic manner. In order to extract water from air conditioner, no need to spend any cost, because water produced as a by-product and trouble production. This cross-sectional study was conducted to evaluate the quantity and chemical quality of water obtained from Bandar Abbas air conditioners; at intervals beginning of March to early December of 2010. Sixty six samples were taken in cluster random plan. Bandar Abbas divided into four clusters; based on distance to shore and population density. Chemical tests which included: Turbidity, alkalinity, total hardness, Dissolved Solids (TDS) and Electrical Conductivity (EC) and quantity measurement were performed on them. Obtained water had slightly acidic $\mathrm{pH}$, near to neutral range. Total dissolved solids, electrical conductivity, total hardness and alkalinity of extracted water were in low rate. Each air conditioner produced 36 liter per day averagely. Split types obtained more water to window air conditioners. With regard to some assumptions, approximately 4680 to 9360 cubic meter per day water is obtainable which is suitable for many municipal and industrial water applications.
\end{abstract}

Keywords: Atmospheric Moisture, Air Conditioner, Water Extraction, Condensation, Bandar Abbas

\section{INTRODUCTION}

Though Water is one of the most abundant natural resources, only $3 \%$ of the world's water is fresh water, less than $1 \%$ of total water is available and the rest are out of reach, in forms of atmospheric vapor, soil moisture, (Lekouch et al., 2011; El-Ghonemy, 2012). Today Shortage of fresh water is a wide-spread problem in arid and semi-arid areas of the world (Habeebullah, 2009; Hamed et al., 2010). Some of the ways which can be cosidered for fresh water supplies in these areas, are transportation of water from other locations, desalination of saline water and extraction of water from atmospheric air (El-Ghonemy, 2012). Among mentioned methods, the atmospheric driven water is considered a huge and renewable source of fresh water. Earth's atmosphere contains $12900 \mathrm{Km}^{3}$ of fresh water; $98 \%$ of these amounts as vapor and $2 \%$ rest in form of clouds (El-Ghonemy, 2012).

Large parts of Iran are located in arid and semi-arid environment. The country is enduring increasing water shortage, which has created many water related problem in these regions (Faramarzi et al., 2010; Tabari and Aghajanloo, 2013). Despite the above conditions, there are the seas in the north and south of Iran, which can be considered as enormous resources. Atmosphere Vapor Processing (AWVP) is another alternative for the water crisis solution. AWVP is a new and emerging technology Corresponding Author: Vali Alipour, Department of Environmental Health En
Tehran University of Medical Sciences, Tehran, Iran 
in which the atmospheric water vapor is condensed and collected (Gandhidasan and Abualhamayel, 2010). There are many places on the planet due to climate conditions (topography and parameters weather), which can be used for atmospheric moisture condensation in as a source for water supply (Sherwood et al., 2010). One of the methods for the atmospheric vapor condensation is usage of equipment with condensation mechanism. usually fresh water extraction by this method requires high cost, which crates huge limitation for usage of them in significant of destitute regions of the world that perchance located in arid or semi arid environment (Beysens et al., 2009; Sharan et al., 2011; MaestreValero et al., 2012).

Significant areas of Iran are located in arid and semi-arid, so the country has been faced with problems related to Water shortage. But in coastal areas of Iran the atmosphere humidity is very high, so in summer humidity even receives to one hundred percent, therefore condensate atmospheric moisture has been noticed for water extraction source in such areas. In coastal cities of Iran south, due to warm and humid climate in a long period of years, air conditioner is used as cooling systems. Air conditioners have two models; window and split-type; Window air conditioners often located in a tray behind a window and there is an outlet for discharging the condensed water in the end of tray. In split-type also there is a pipe for condensation water discharge. By collection and managing of this water it can be response a part of community water demand. In home air water recovery is a by-product yield which any cost for this water production is not necessary; hence the use of this water can be very efficient.

In the past studies, water production as a byproduct of air conditioners has been considered as an idea for the fresh water supply in warm and humid climates (Narayan et al., 2010). Many studies in the field of water harvesting from atmospheric moisture has been performed that in all studies atmosphere moisture has been introduced as a reliable source of water supply (Habeebullah, 2009; Liang et al., 2009; Yuana et al., 2011; Licina and Sekhar, 2012). Al-Hassan (2009) study, obtain an average water production of $6.215 \mathrm{~L} / \mathrm{m}^{2}$ day is reported.

The purpose of this study was to survey quality and quantity of mentioned by-product water in order to develop management programs for optimal use of this permanent source of water, based on qualitative and quantitative specifications.

\section{MATERIALS AND METHODS}

This cross-sectional study was conducted to evaluate the quantity and chemical quality of water obtained from Bandar Abbas (BA) air conditioners. BA is located in Hormozgan province, south of Iran. Total sample numbers in this study were sixty six. Sampling plan was cluster random; each cluster was one of BA regions. In this classification BA was divided into four clusters, based on distance to shore and population density. Cluster 1 includes the coastal areas with high population density and vehicle traffic. Cluster no 2 includes the coastal areas with low population density and vehicle traffic. Cluster no 3 includes offshore areas with high population density and traffic vehicles and finally cluster no 4 includes offshore areas with low population density (Fig. 1).

Based on the area covered by each clusters, sample number for each region was determined, thus 14, 16, 17 and 19 samples were taken from cluster 1 to 4 , respectively. In order to consider the seasonal conditions in the study, the samples were taken in a 9 period time; at intervals beginning of March to early December of 2011.

In order to sampling for chemical parameter tests, plastic bottles with a capacity of 1.5 liter which previously washed with distilled water were used. The bottles located on the desired locations and then transported to the laboratory in determined time period. Plastic containers with a capacity of 20 liters were used for quantity tests and collected water amounts was measured using a calibrated gauge two times per day. After sampling, samples were sent to laboratory for tests which included: Turbidity, alkalinity, total hardness, Dissolved Solids (TDS) and Electrical Conductivity (EC).

Hardness and Alkalinity measurements using titration methods and reagents made by Merck company, expire date by end of 2012, based on standard No c 2340 of the standard reference method were performed (Apha, 2012). Measurement of $\mathrm{pH}$ using $\mathrm{pH}$ meter Elmetron Model CP-501 was conducted by using the method specified in the catalog system. EC and TDS samples using TDS meter model Aqualytic CD24 and turbidity using a turbidity meter Hach Model 2130B were measured. Alkalinity measurements using titration methods and reagents made by Merck company, expire date by end of 2014, based on standard No B 2320 of the standard method were Performed (Apha, 2012). After receiving data from experiments using Central Statistical parameters (mean, Standard deviation and t SD test) and results were analyzed using SPSS. 


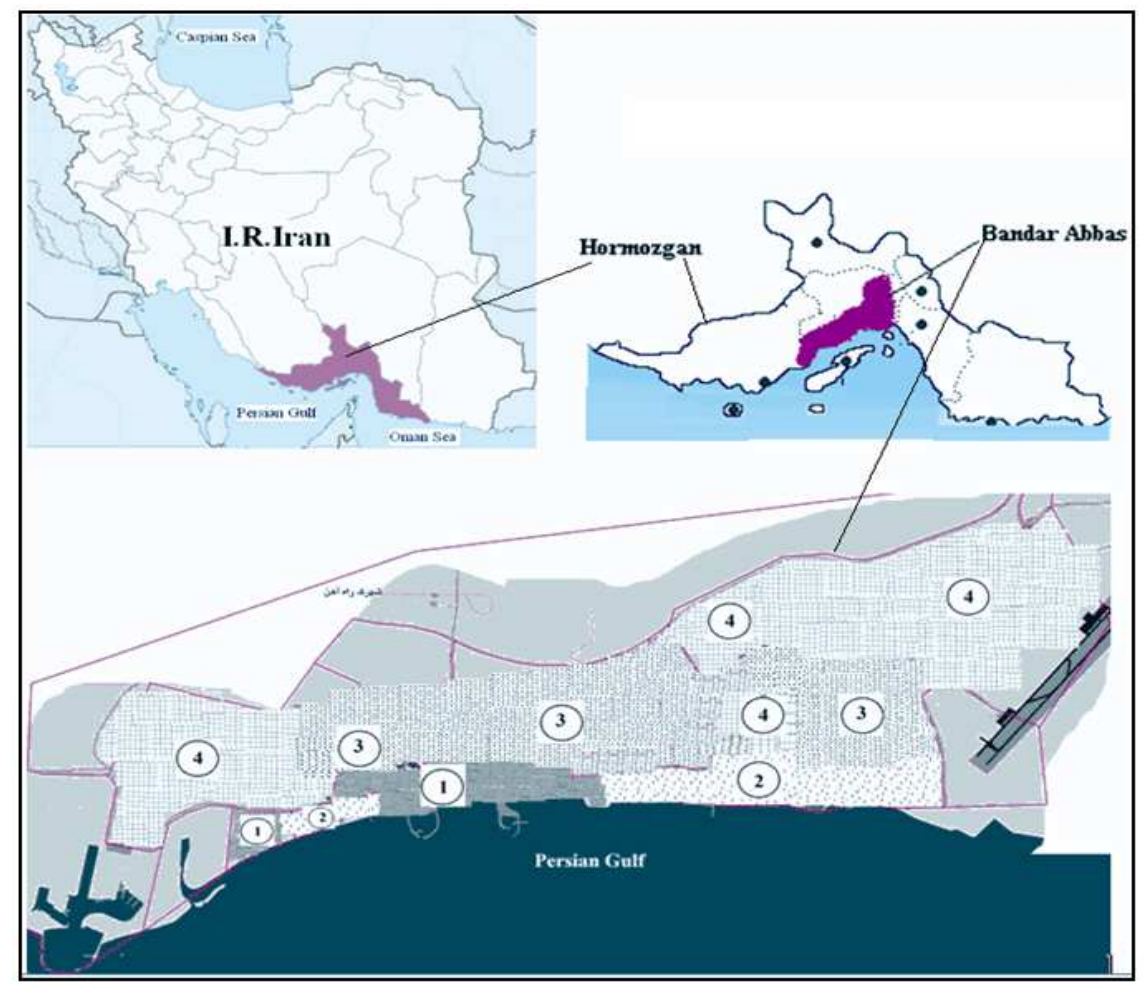

Fig. 1. Geographical location of Bandar Abbas and Classification of Bandar Abbas on the four areas

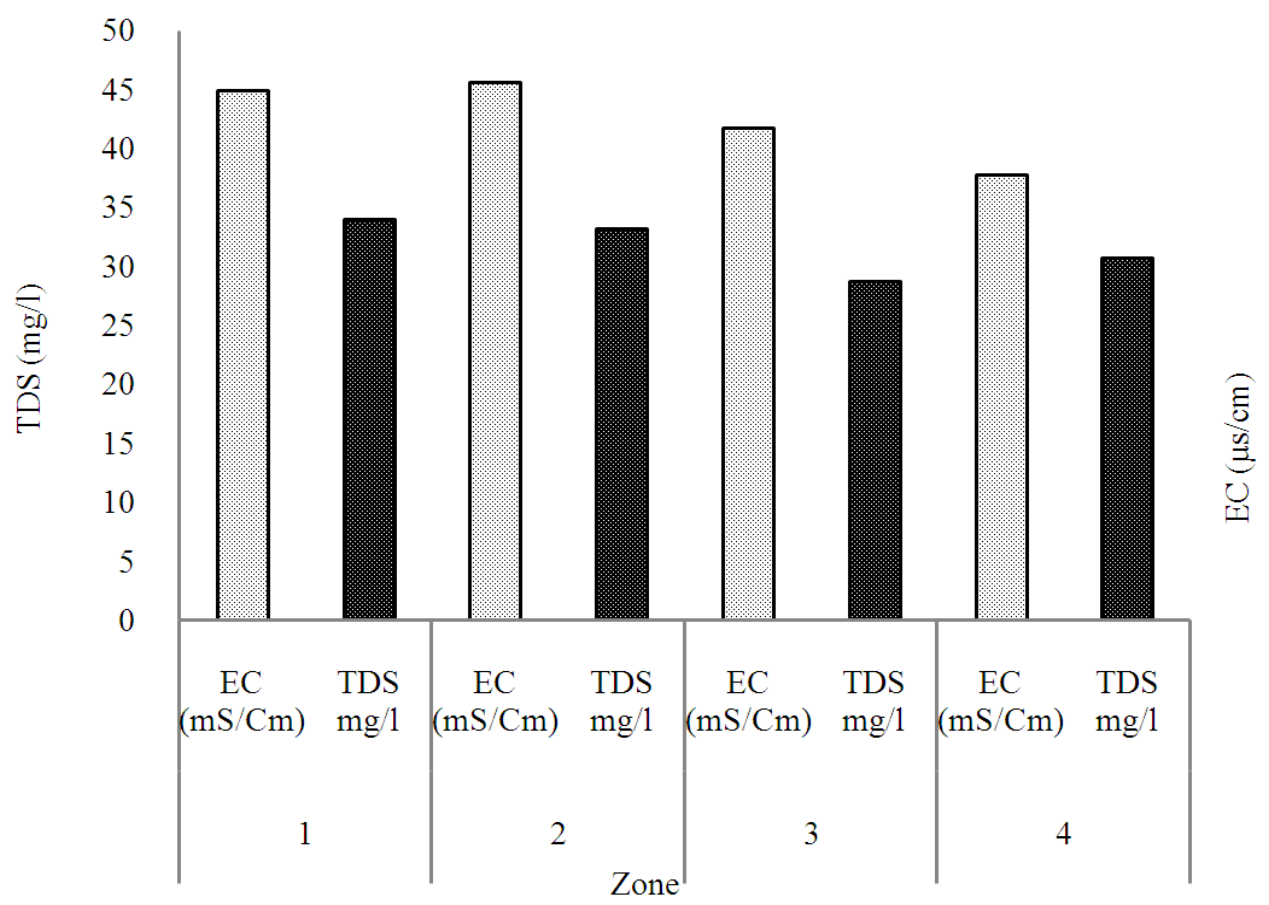

Fig. 2. Average values for TDS and EC of air conditioner water condensate in BA 


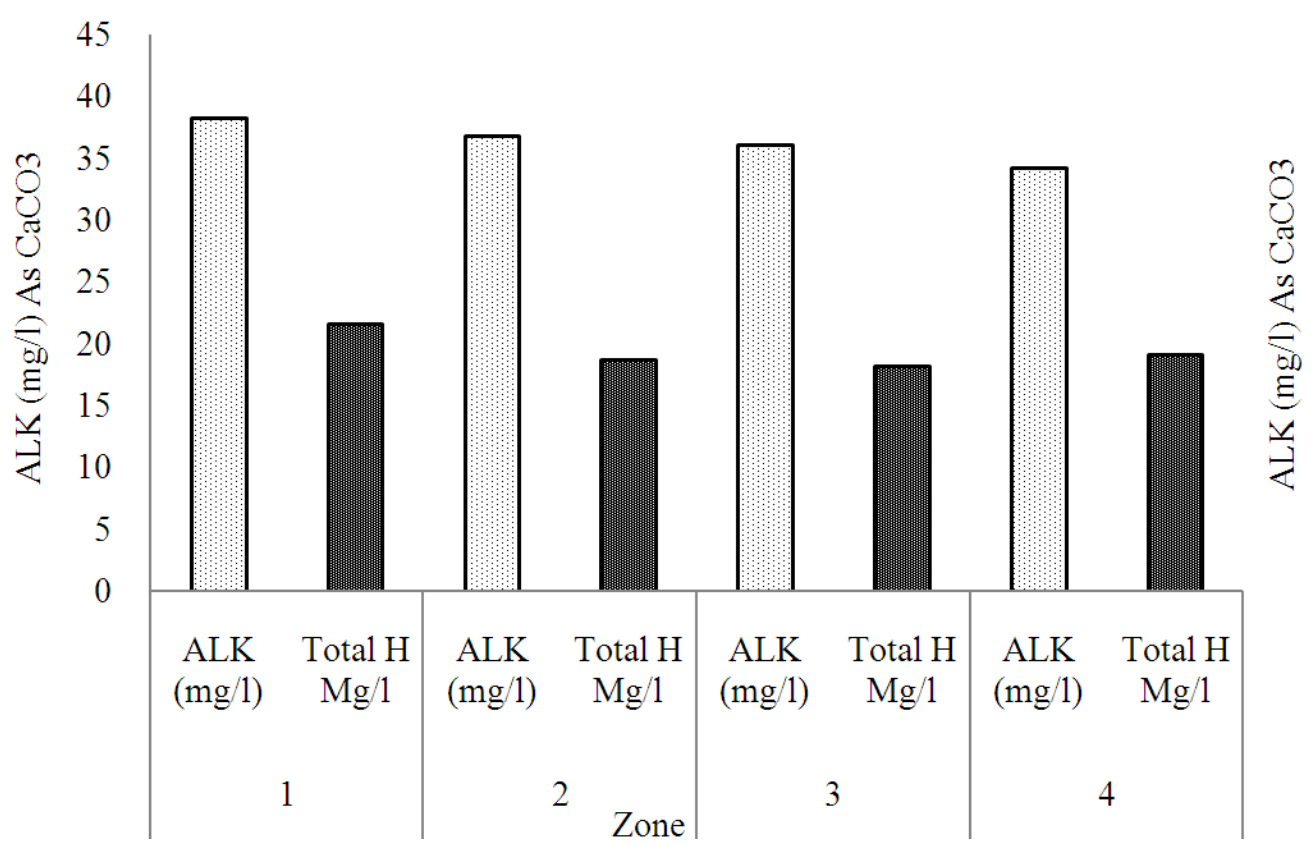

Fig. 3. Average values for Total hardness and Alkalinity of air conditioner water condensate in BA

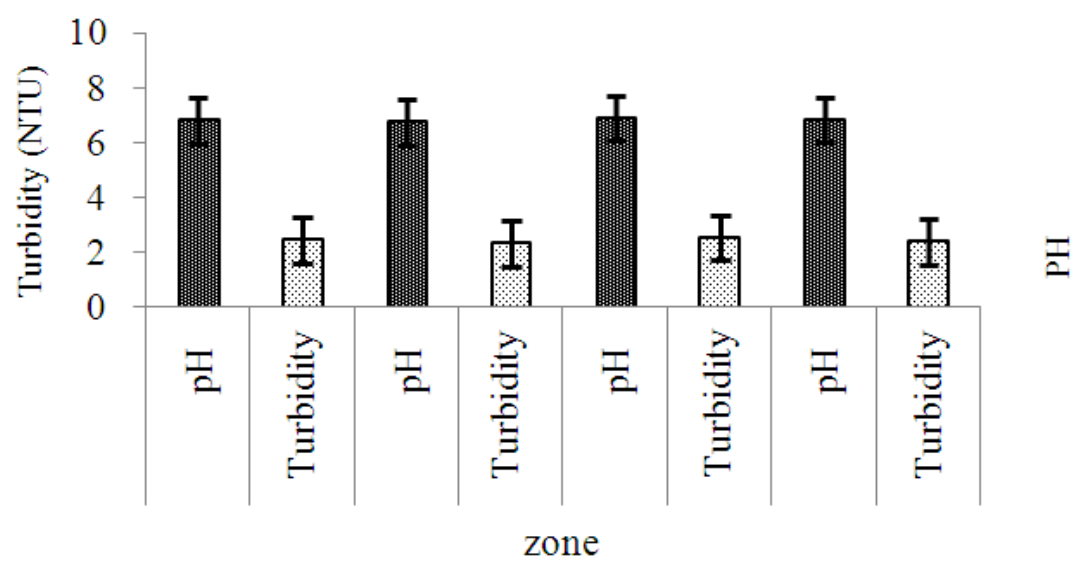

Fig. 4. Average values for turbidity and $\mathrm{pH}$ of air conditioner water condensate in BA

Table 1. Quantity of produced water by each home air conditioner in Quarter periods (1/d)

\begin{tabular}{|c|c|c|c|c|c|c|c|c|c|c|c|c|}
\hline \multirow{3}{*}{$\begin{array}{l}\text { zone } \\
\text { Sampling } \\
\text { Duration }\end{array}$} & \multicolumn{3}{|l|}{ Zone 1} & \multicolumn{3}{|l|}{ Zone 2} & \multicolumn{3}{|l|}{ Zone 3} & \multicolumn{3}{|l|}{ Zone 4} \\
\hline & Quarter & Quarter & Quarter & Quarter & Quarter & Quarter & Quarter & Quarter & Quarter & Quarter & Quarter & Quarter \\
\hline & 1 & 2 & 3 & 1 & 2 & 3 & 1 & 2 & 3 & 1 & 2 & 3 \\
\hline Number & 14.0 & 14.0 & 14.0 & 15.0 & 15.0 & 15.0 & 17.0 & 17.0 & 17.0 & 19.0 & 19.0 & 19.0 \\
\hline Mean & 33.4 & 47.1 & 29.1 & 33.8 & 47.6 & 21.3 & 30.4 & 44.9 & 30.1 & 31.0 & 45.1 & 28.7 \\
\hline Std Dev & 3.7 & 4.3 & 3.0 & 3.8 & 5.0 & 2.5 & 3.30 & 5.1 & 2.2 & 3.6 & 4.2 & 3.00 \\
\hline Min & 27.9 & 40.3 & 24.7 & 28.0 & 40.3 & 24.7 & 24.7 & 37.1 & 24.9 & 26.0 & 36.4 & 23.4 \\
\hline $\operatorname{Max}$ & 37.9 & 52.7 & 33.8 & 39.7 & 55.3 & 32.5 & 35.1 & 52.7 & 34.5 & 37.1 & 51.4 & 33.8 \\
\hline
\end{tabular}




\section{RESULTS}

Two types of results collected from BA air conditioners; chemical quality and quantity of condensate water. Quality results were shown in Fig. 2-4.

Results of quantity measurements is reported in 3 time periods; period one is time duration from beginning March to early June, period 2 from beginning June to early September and period 3 was from beginning of September to early December. The collected data of these parts were shown in Table 1.

\section{DISCUSSION}

According to the results, $\mathrm{pH}$ of extracted water is slightly acidic; close to neutral range, it would be related to the presence of gases and especially carbon dioxide is in the air. Test t-test showed no significant difference between the mean $\mathrm{pH}$ in the four regions $(\mathrm{p}>0.05)$.

The average turbidity measurements showed that the minimum and maximum average of turbidity is 2.35 and 2.55 NTU respectively. Minimum measurements for turbidity were related to low population density region close to the beach and the maximum measured in the high density away from the beach. Test t-test significant differences between mean turbidity was observed $(\mathrm{p}<0.05)$. We supposed turbidity of extracted water is close to zero, same as pure water, while results showed a significant value for turbidity. It would because of suspended particles of dust presence in BA air; the second factor can also be related to the particle emissions from vehicles. As was stated previously, the low traffic and high-traffic locations, there was a significant difference.

As presented in Fig. 2, there is a significant differences between both electrical conductivity and total dissolved solids in regions close to the beach and away from the beach, $(\mathrm{p}<0.05)$. The average electrical conductivity and total dissolved solids of water in the area is close to the beach is more than away from the beach. This could be due to dissolution of salts from the sea which presents in water droplets in the atmosphere above the sea.

As Fig. 4 shows, alkalinity range was $17-22 \mathrm{mg} \mathrm{L}^{-1}$ as $\mathrm{CaCO} 3$ which classified into low alkalinity waters category. Minimum and maximum hardness values were measured 36 and $41 \mathrm{mg} \mathrm{L}^{-1}$ as CaCO3respectively. Based on these values, the water classified into very soft category and water can cause corrosion of metal in contact, so it is necessary in this type of water consumption, to be noticed.
Table 2. water quality indices for different industrial use (mg/l)

\begin{tabular}{lllll}
\hline Parameter & LSG & RSG & SG & VSG \\
\hline $\mathrm{Fe}$ & $0-1$ & $0-0.3$ & $0-0.1$ & $0-0.05$ \\
$\mathrm{Mn}$ & $0-1$ & $0-0.3$ & $0-0.05$ & $0-0.01$ \\
$\mathrm{Ph}$ & $5-10$ & $5-10$ & $6-10$ & $7-9$ \\
Hardness & $0-500$ & $0-250$ & $0-10$ & $0-5$ \\
Alkalinity & $0-500$ & $0-150$ & $0-100$ & $0-50$ \\
Sulphate & $0-500$ & $0-250$ & $0-75$ & $0-20$ \\
Silica & $0-50$ & $0-250$ & $0-100$ & $0-5$ \\
TSS & $0-100$ & $0-10$ & $0-5$ & $0-1$ \\
TDS & - & $0-500$ & $0-100$ & $0-50$ \\
\hline * Lowest & Sensitivity Group (LSG), Sensitive Group (SG), \\
Relatively & Sensitive Group (RSG), Very Sensitive Group \\
(VSG) & \multicolumn{5}{c}{}
\end{tabular}

Bandar Abbas has about five hundred thousand population and the average family size for 5 people. By suppose of 1-2 air conditioners per each household, 100,000 to 200,000air conditioners are exists in BA. The average of extracted water per unit in the four regions is about 36 liters per day. With these assumptions, can be estimated about 4680 to 9360 cubic meters per day, water can be extracted from BA air conditioners. The production rate of water in split-type air conditioners was more than of window types and the difference between them also were significant $(p<0.05)$. This difference in the quantity of extracted water between two air conditioner types would be related to appropriate collection system in a variety of split-type air conditioners, while in the window types, the water initially collected in a tray and then be transferred by a pipe or hose. Thus evaporation of water in trays or leak from the tray or pores is a reason for less water production in the window types. Perhaps the major reason for the difference in the amount of water production in the two types of air conditioners is related to higher efficiency in split-type air conditioners. Due to public interest increment in the split-type air conditioners, it is predicted to increase the extraction of water from the air conditioners, therefor the planning for this significant amount of water, it would be economically justified.

As mentioned earlier, no excess fee or energy is necessary for water production in this method which is a significant advantage of this method. Considering that the coastal cities of southern Iran are often located in shortage water areas, this water can be considered as a valuable source for a large variety of urban and industrial consumptions, exclusion of drinking needs (Abro et al., 2009). According to tests carried out, the water quality is suitable to many municipal uses such as irrigation, landscaping, swimming pools and water parks, water for building construction, firefighting and car washes and so 
on. Also with matching quality chemical extracted water to the values listed in Table 2 which is related to the standards of industrial water in Iran. It can be finding; excluding very sensitive group, extracted water has good quality for all needs of water industries. In order to ensure the microbial safety of the condensate water, recommended amount of 5 grams per cubic meter of per chlorine powder to be added to the water.

\section{CONCLUSION}

Basically for judgments about a source of water for the water some principle such as the impact on health, quality products, cost of treatment, type and surface treatment technology and its effects on biodiversity have to be considered. The chemical quality of the tested samples can be said, the water after a simple disinfection, will have no adverse effect on consumers health (of course plenty of water for drinking without treatment is not recommended). As mentioned later, the condensate water has suitable quality for many of industrial uses while this water source is free; no cost for treatment is necessary, no adverse effects on environment, no harmful effects for equipment and no health risks. At this time, the mentioned water not only is useful for any use, but also by dripping on the floor crates aesthetical and cognitive health problems for residents of these areas. Therefore it is requires a comprehensive plan and codified it into the water collection, storage and end it best used as directed.

\section{REFERENCES}

Abro, A., S. Ahmed, M. Claxton, N. Hazariwala and C. Hesser et al., 2009. Design a system to recycle condensate from residential air conditioners (Semester Unknown) IPRO 348. Illinois Institute of Technology.

Al-Hassan, G.A., 2009. Fog water collection evaluation in Asir Region-Saudi Arabia. Water Resou. Manage., 23: 2805-2813. DOI: 10.1007/s11269-009-9410-9

Apha, W., 2012. Standard Methods for the Examination of Water and Wastewater. 22nd Edn., American Public Health Association, Washington, ISBN-10: 0875530133, pp: 1496.

Beysens, D., I. Lekouch, M. Mileta, I. Milimouk and M. Muselli, 2009. Dew and rain water collection in south Croatia. Int. J. Civil Environ. Eng., 51: 64-70.

El-Ghonemy, A.M.K., 2012. Retraction notice to "Fresh water production from/by atmospheric air for arid regions, using solar energy: Review". Renew. Sustain. Energy Rev., 16: 6384-6422.
Faramarzi, M., H. Yang, J. Mousavi, R. Chulin and C.R. Binder et al., 2010. Analysis of intra-country virtual water trade strategy to alleviate water scarcity in Iran. Hydrol. Earth Syst. Sci., 14: 1417-1433. DOI: 10.5194/hess-14-1417-2010

Gandhidasan, P. and H.I. Abualhamayel, 2010. Investigation of humidity harvest as an alternative water source in the Kingdom of Saudi Arabia. Water Environ. J., 24: 282-292. DOI: 10.1111/j.17476593.2009.00189.x

Habeebullah, B.A., 2009. Potential use of evaporator coils for water extraction in hot and humid areas. Desalination, 237: 330-345. DOI: 10.1016/j.desal.2008.01.025

Hamed, A.M, A.E. Kabeel, Z. E-Shafei and A.A. Aly, 2010. Technical review on the extraction water from atmospheric air in arid zones. J. Heat Mass Trans., 4: 213-228.

Lekouch, I., M. Muselli, B. Kabbachi, J. Ouazzani and I. Milimouk et al., 2011. Dew, fog and rain as supplementary sources of water in south-western Morocco. Energy, 36: 2257-2265. DOI: 10.1016/j.energy.2010.03.017

Liang, Z., L.D. Wei and J.X. Li, 2009. Feasibility analysis of air conditioning condensation water and harvesting rainwater combine system.

Licina, D and C. Sekhar, 2012. Energy and water conservation from air handling unit condensate in hot and humid climates. Energy Build., 45: 257-263. DOI: 10.1016/j.enbuild.2011.11.016

Maestre-Valero, J.F., R. Ragab, V. Martínez-Alvarez and A. Baille, 2012. Estimation of dew yield from radiative condensers by means of an energy balance model. J. Hydrol., 460-461: 103-109. DOI: 10.1016/j.jhydrol.2012.06.046

Narayan, G.P., M.H. Sharqawy, E.K. Summers, J.H. Lienhard and S.M. Zubair et al., 2010. The potential of solar-driven humidification-dehumidification desalination for small-scale decentralized water production. Renew. Sustain. Energy Rev., 14: 11871201. DOI: 10.1016/j.rser.2009.11.014

Sharan, G., O. Clus, S. Singh, M. Muselli and D. Beysens, 2011. A very large dew and rain ridge collector in the Kutch area (Gujarat, India). J. Hydrol., 405: 171-181. DOI: 10.1016/j.jhydrol.2011.05.019

Sherwood, S.C., R. Roca, T.M. Weckwerth and N.G. Andronova, 2010. Tropospheric water vapor, convection and climate. Rev. Geophys. DOI: 10.1029/2009RG000301 
Amir Hossein Mahvi et al. / American Journal of Applied Sciences 10 (8): 917-923, 2013

Tabari, H. and M.B. Aghajanloo, 2013. Temporal pattern of aridity index in Iran with considering precipitation and evapotranspiration trends. Int. J. Climatol., 33: 396-409. DOI: 10.1002/joc.3432
Yuana, G., Z. Wang, H. Li and X. Li, 2011. Experimental study of a solar desalination system based on humidification-dehumidification process. Desalination, 277: 92-98. DOI: 10.1016/j.desal.2011.04.002 